\title{
Disaster recovery via social capital
}

\author{
Social capital, embedded in people's relationships, is important for practically all domains of life. Individuals need \\ others to safeguard and enhance their living conditions. A study now shows that social capital helps in the recovery \\ from a natural disaster.
}

\section{Beate Völker}

$\Lambda$ major field in social science research is the study of resources that are crucial for getting ahead. The unequal distribution of such resources explains the persistence of social inequality and class boundaries. Attention has long been paid to human capital - a concept introduced by Alfred Marshall ${ }^{1}$ and elaborated theoretically by the economist Gary Becker ${ }^{2}$ - which identifies a person's resources, such as knowledge, intelligence, or experience, as assets for potential employers. Later, the famous German social theorist Max Weber ${ }^{3}$ was among the first to distinguish different types of resources that safeguard and enhance what he called people's 'life chances'. For Weber, resources like economic and human capital, along with political power and symbolic capital (based on honour, recognition and prestige), explain people's status and, more broadly, all of the opportunities to move upward that they are faced with in life. Sociologists added social capital to this list of resources as it also predicts and explains who will successfully climb the social ladder.

Social capital refers to all of the benefits, favours, information and the like that are available to people through their contacts. It helps people to achieve goals that are otherwise much more costly or even unobtainable ${ }^{4}$. In modern empirical sociology, social capital has been amply studied, and its value for disparate domains of people's lives is well-established. For example, social capital helps individuals to get a job, a place to live, a car, and other high-priced consumer goods. Likewise, it matters for staying healthy or participating in a neighbourhood community. Social science research has generally demonstrated that people mutually depend on each other and that there are tight limits to what one can achieve alone. This dependency varies with social institutions, which affect people's need for help and promote the creation of supportive networks.

Importantly, research into social capital questions the idea of a society that is based on merits and universalism: it shows that who you know and by whom you are

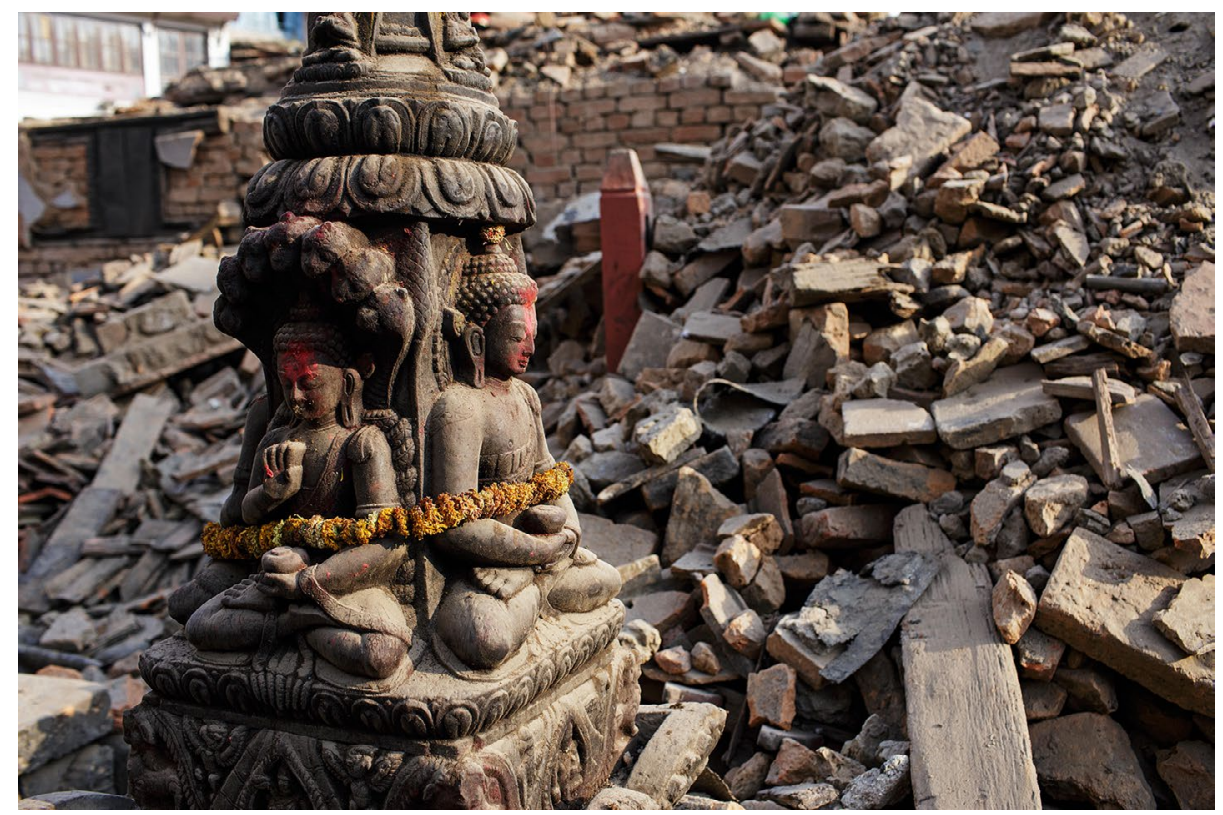

Credit: Maciej Dakowicz / Alamy Stock Photo

known matter - in some cases, even more than what you know. The concept has multiple, important dimensions, including an individual one and a collective one, and there are several ways to measure it, many of which are well established. A common measure of collective social capital is the density of a community. On the individual level, besides direct contacts, social capital is enriched by connections with representatives of social institutions, markets and state representatives, or membership of groups and organizations.

Writing in Nature Sustainability, Arun Agrawal $^{5}$ and colleagues use these three indicators of an individual's social capital to investigate the economic recovery of households who were affected by the 2015 earthquakes in Nepal. They show how both social and human capital predict recovery from the disaster. The authors were in a unique position to build a rare longitudinal dataset, with data collected both before and after the earthquake, which helped them to establish how social and human capital interact. An analytically innovative application of Bayesian additive regression trees (BART) allowed them to simulate the hypothetical income of households in the absence of the earthquake. Moreover, they conducted a so-called placebo test with data on human and social capital from 2012 to predict income changes in the subsequent three years.

Agrawal and colleagues find that higher levels of both human and social capital helped households to recover financially from the shock caused by the catastrophe. Households that scored high on both types of capital were clearly better off. Regarding complementarity between social and human capital, higher levels of the latter predicted better income recovery than higher levels of the former: households high in human capital but low in social capital recovered better than households with low human but high social capital. 
Nevertheless, the benefits of social capital were significant but not homogeneous: they were greater for those in the lower social strata than for the higher-positioned households. For households with lower levels of education (less than seven years of schooling), social capital predicted income recovery, whereas it did not show additional benefits for those with more education. This particular finding is new and intriguing. Most studies in the social sciences have established the so-called 'Matthew effect', whereby social capital magnifies the benefits of human capital ${ }^{4,6}$. This effect deepens the social divides - the rich get richer. This is because social capital is usually associated with reciprocity, and those with many resources are attractive contacts as they can reciprocate help. However, the results by Agrawal and colleagues underscore that building social capital is particularly valuable for those who lack other resources. Hence, the disadvantage of a low education is, in this case, partially compensated by social capital.
Crucially, social capital may be the only resource left in times of crisis, but it is important to note that social capital needs to be acquired beforehand. It is created through long-term investment in nurturing networks and through establishing linkages to the institutions of a society. It is almost impossible to establish significant social capital instantly during an emergency. As seen with the stock market, it takes time to make returns on investments.

Although not immediately generalizable, these results may also shed light on the importance of social capital in other crises, such as the COVID-19 pandemic. In such unexpected situations, resilience is not only determined by people's cognitive or financial resources. Social resources have a profound impact, and their value becomes visible. Policy makers can apply this knowledge by stimulating ties among people and between people and institutions, such as by creating meeting opportunities and facilitating repeated interactions. People without many other resources should be particularly encouraged to build social capital by participating in social institutions and becoming members of organizations or associations. After all, a tie established through participation can make the difference when resilience is most needed.

Beate Völker (D) 凶

Human Geography and Spatial Planning, Utrecht University, Utrecht, the Netherlands.

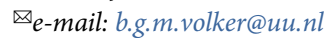

Published online: 2 December 2021 https://doi.org/10.1038/s41893-021-00820-5

References

1. Marshall, A. Principles of Economics Variorum Edition (Macmillan, 1961)

2. Becker, G. S. J. Polit. Econ. 70, 9-49 (1962).

3. Weber, M. Wirtschaft und Gesellschaft. Grundriß der Verstehenden Soziologie (Tübingen, 1985).

4. Coleman, J. S. Foundations of Social Theory (Belknap Press, 1990).

5. Liu, W., Gerber, E., Jung, S. \& Agrawal, A. Nat Sustain. https://doi. org/10.1038/s41893-021-00805-4 (2021).

6. Rigney, D. The Matthew Effect: How Advantage Begets Further Advantage (Columbia Univ. Press, 2010).

Competing interests

The author declares no competing interests. 